\title{
Supraclavicular Artery Flap for Oral Reconstruction Prior to Esophagectomy During the COVID-19 Pandemic: A Case Report
}

\author{
HIDENORI SUZUKI $^{1}$, SHO IWAKI ${ }^{1}$, EIJI HIGAKI ${ }^{2}$, TETSUYA ABE ${ }^{2}$, MICHI SAWABE ${ }^{1}$, SHINTARO BEPPU ${ }^{1}$, \\ YOSHIAKI KOBAYASHI ${ }^{1}$, DAISUKE NISHIKAWA ${ }^{1}$, HOSHINO TERADA $^{1}$ and NOBUHIRO HANAI ${ }^{1}$ \\ ${ }^{1}$ Department of Head and Neck Surgery, Aichi Cancer Center Hospital, Nagoya, Japan; \\ ${ }^{2}$ Department of Gastroenterological Surgery, Aichi Cancer Center Hospital, Nagoya, Japan
}

\begin{abstract}
Background: During the coronavirus disease 2019 (COVID19) pandemic, pedicle flaps (instead of free flaps) were recommended for reconstruction following wide resection for patients with head and neck cancer, in order to reduce the use of medical resources. Currently, there are no established treatment guidelines for patients with head and neck cancer with synchronous esophageal cancer. Case Report: We present a 68-year-old male with cT4aN2cM0 oral floor and synchronous cT1bN1MO esophageal cancers who had defective reconstruction following oral tumor resection before esophagectomy during the pandemic. At the initial surgery, the oral resected defect was reconstructed using supraclavicular artery flap. The subsequent esophagectomy was reconstructed by gastric tube reconstruction. Both postoperative courses were successful, without the need for postoperative ventilator use. The days from initial or second surgery to discharge were 14 or 16 days, respectively. Conclusion: This case had achieved negative surgical margins and recovered oral intake with tracheostomy decannulation. Further case accruement using supraclavicular artery flap is required for patients with head and neck cancer and synchronous esophageal cancer.
\end{abstract}

During the coronavirus disease 2019 (COVID-19) pandemic first reported in December 2019 (1), surgeons were

This article is freely accessible online.

Correspondence to: Hidenori Suzuki, MD, Ph.D., Department of Head and Neck Surgery, Aichi Cancer Center Hospital, 1-1 Kanokoden, Chikusaku, Nagoya, 464-8681. Japan. Tel: +81 527626111, Fax: +81 527642963, e-mail: hi.suzuki@aichi-cc.jp

Key Words: COVID-19, head and neck cancer, synchronous esophageal squamous cell carcinoma, supraclavicular artery flap, decannulation. recommended to use pedicle flaps instead of free flaps for reconstruction following the resection of advanced tumors in head and neck cancer (HNC) (2, 3). Before this, supraclavicular artery flap (SAF) with a long regional pedicle was widely indicated as safe reconstruction of resected defects from neck to temporal bone in patients with HNC for decades (4-6). Changes to surgical practices resulted from the relative benefits of utilizing fewer medical resources by using SAF of $\mathrm{HNC}$ reconstruction during the COVID-19 pandemic $(7,8)$. However, to the best of our knowledge, guidelines have not incorporated SAF into treatment strategies for $\mathrm{HNC}$ with synchronous esophageal cancer (EC) before and during the pandemic $(9,10)$. Herein, we report a patient with advanced HNC with synchronous EC who underwent SAIF to reconstruct a resected oral floor before esophagectomy during the ongoing pandemic.

\section{Case Report}

This case report was approved by the review board of Aichi Cancer Center (receipt number: 2021-1-050) according to the Declaration of Helsinki. Written informed consent to publish was obtained from the patient. A 68-year-old male with the subjective symptom of a right oral tumor that consulted a previous hospital, had an esophageal tumor detected by18Ffluorodeoxyglucose positron emission tomography with computed tomography (CT). Visual inspection and palpation at our hospital revealed an oral floor tumor measuring $34 \mathrm{~mm}$ at its largest diameter. Subsequently, an enhanced CT and magnetic resonance imaging showed lymph-node metastasis into the left submandibular lymph nodes and mandibular bone invasion. Enhanced CT also detected a lymph-node metastasis of cervical paraesopharynx. Moreover, endoscopy illustrated thoracic esophageal tumors with cT1b. All biopsy specimens from the oral floor and esophageal tumor were pathologically diagnosed as squamous cell carcinoma (SCC). Using the eighth edition of Union for International Cancer Control, the 

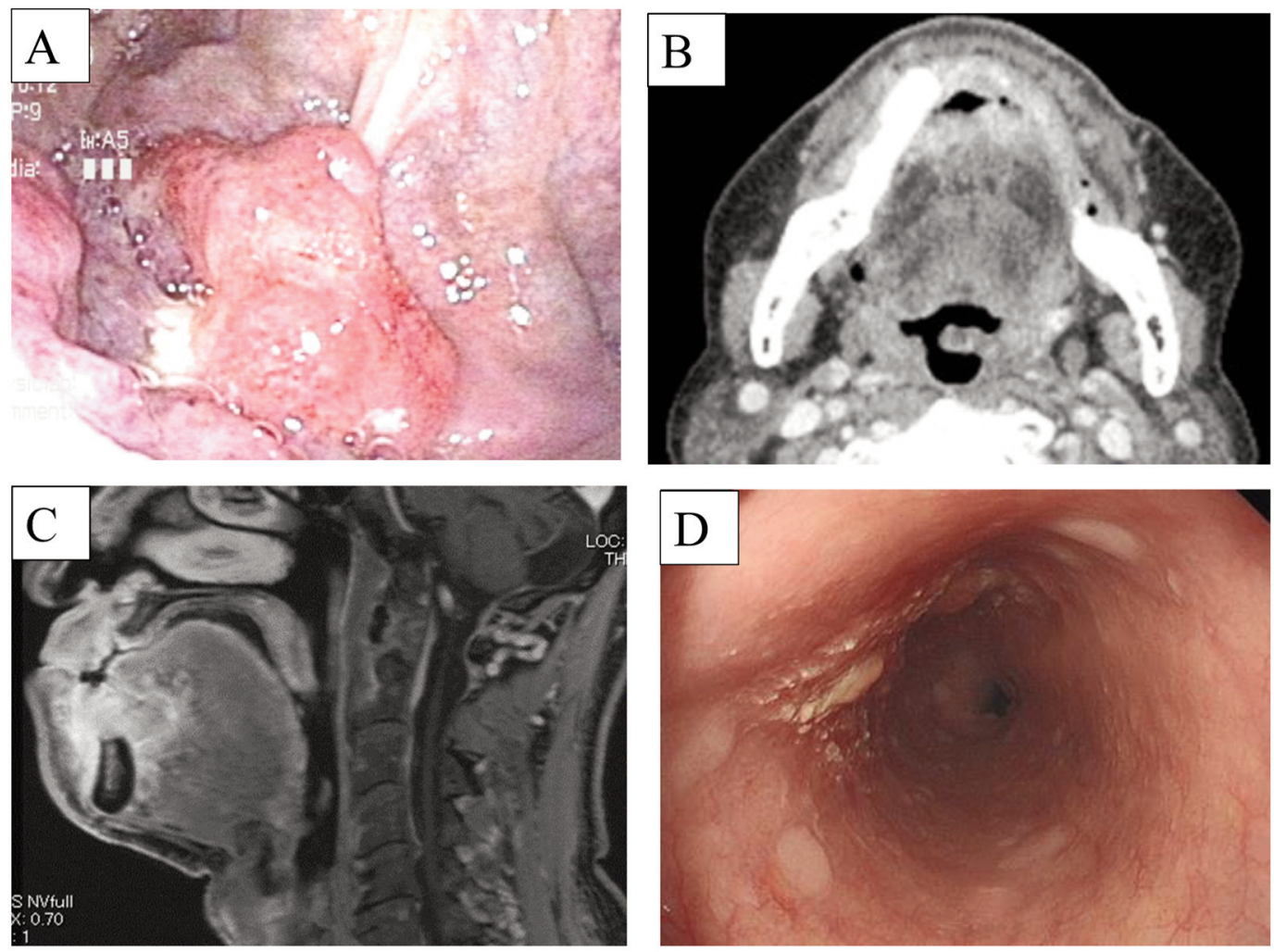

Figure 1. Pretreatment images. (A) White light image, (B) enhanced computed tomography, and (C) enhanced magnetic resonance imaging in the oral floor tumor. (D) Endoscopy in esophageal tumor.

patient's diagnosis was cT4aN2cM0 (Stage IV) oral floor SCC with cT1bN1M0 (Stage I) esophageal SCC. Figure 1 shows the patient's pretreatment images.

A multidisciplinary team recommended initial treatment of the oral floor SCC and later esophagectomy with gastric tube reconstruction due to the SCC's advanced tumor stage relative to the esophageal SCC. The oral tumor was then resected following marginal mandibulectomy with both tracheostomy and bilateral neck dissection ranging from level I-IV. It was difficult to primarily suture the resultant wide defect following the oral resection. Therefore, one head and neck surgeon and three residents at the Department of Head and Neck Surgery performed the SAF reconstruction. Following the confirmation of the location for both transverse artery and external jugular vein in the neck dissection range, surgeons designed a broad pedicle flap measuring $22 \times 7 \mathrm{~cm}$ in the posterior cervical triangle, demarcated anteriorly by the posterior edge of the sternocleidomastoid muscle, inferiorly by the clavicular, and posteriorly by the anterior trapezius muscle. The flap, with both its fascia and periosteum, was elevated from its distal to proximal end over the deltoid and trapezius muscles. After preserving the accessory nerve and cutting the distal end of the omohyoid muscle, the elevated flap was rotated and tunneled under the sternocleidomastoid muscle with tension free toward the oral defect by cutting the area surrounding the fascia without pedicle skeletonization. Afterwards, the skin paddle of the tunneled flap measuring $9 \times 7 \mathrm{~cm}$ was tested using a pin prick for vascularization, and the tunneled flap was returned from under the sternocleidomastoid muscle and deepithelialized. The deepithelialized flap was carefully sutured to cover the defect using simple closure without tension. The resultant defect was primarily closed using negative pressure drain after extensive undermining. Figure 2 shows images from the initial surgery.

The immediate postoperative period was ventilator free. There was no flap necrosis or fistula. Wound drains were removed on $4^{\text {th }}$ postoperative day (POD). The tracheostomy tube and nasogastric tube were decannulated on the $12^{\text {th }}$ POD after the patient could take food orally. The patient was discharged on the $14^{\text {th }}$ POD with a pathological diagnosis of pT4aN3bM0 oral floor SCC with tumor negative surgical margins.

On the $66^{\text {th }}$ POD following initial surgery, no recurrence or metastasis were detected in the enhanced/plane wholebody CT images. A second surgery to remove the esophageal 

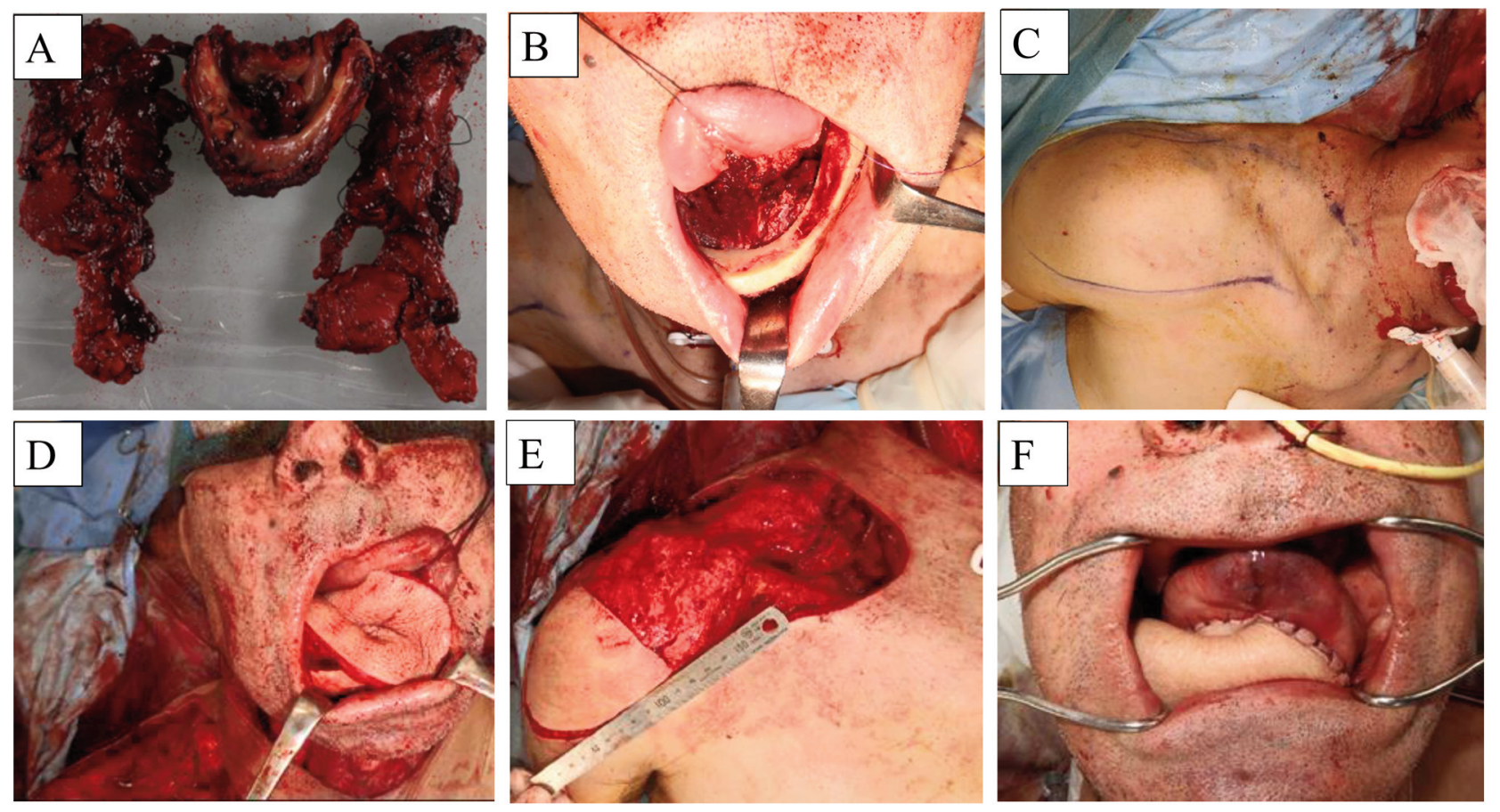

Figure 2. Images of the first surgery. (A) Surgical specimen, (B) oral resected defect, (C) design of supraclavicular artery flap, (D) tunneled flap, (E) deepithelialized flap and $(F)$ sutured flap at initial surgery.
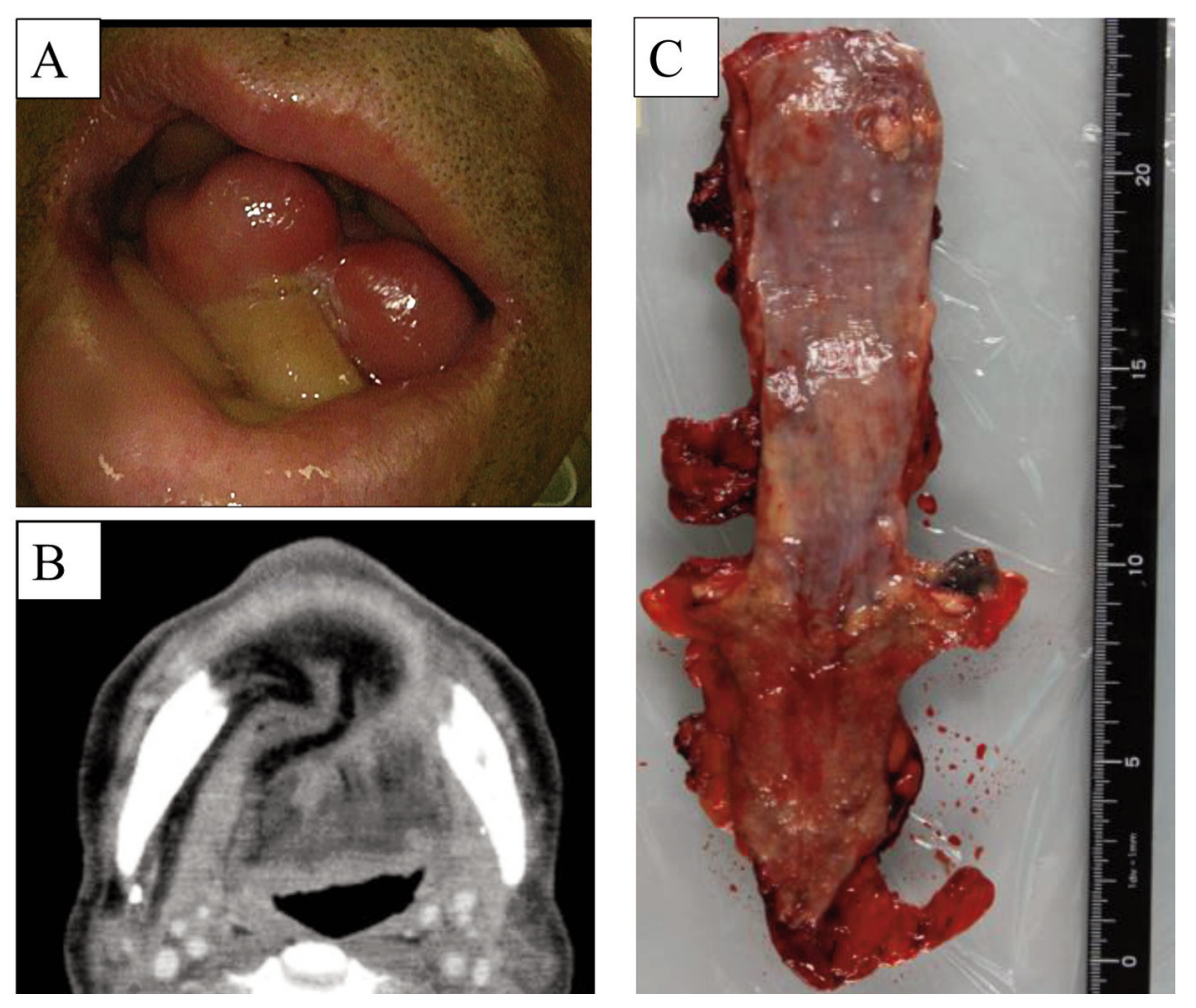

Figure 3. Images of the second surgery. (A) White light image, (B) enhanced computed tomography of the reconstructed oral floor, and (C) surgical specimen at the second surgery. 
SCC was performed. Surgeons performed thoracoscopic esophagectomy with lymph-node dissection and gastric tube reconstruction. The patient was immediately extubated in the operating room, and there were no paralysis resulting from injury of the recurrent laryngeal nerve. Oral intake commenced on the $8^{\text {th }}$ POD, and the patient was discharged on the $18^{\text {th }}$ POD following the $2^{\text {nd }}$ surgery. The patient's pathological diagnosis was pT1N2M0 esophageal SCC with tumor negative surgical margins. Figure 3 shows second surgical images.

On the $202^{\text {nd }}$ POD following the initial surgery, the decannulated patient completely resumed oral intake recovery and received chemotherapy comprised of cisplatin, 5-fluorouracil, and pembrolizumab due to recurrence of the oral floor SCC with crT3N1M1. Throughout the patient's clinical course, his antigen test for COVID-19 was negative.

\section{Discussion}

SAF for patients with HNC was discovered in an attempt to develop safe procedures $(4,5)$; its safety has been confirmed by several surgeons $(5,6)$. The SAF pedicle has been increasingly preserved as surgeons moved from radical dissection procedures to selective neck dissection for patients with HNC (11). The rate of total flap loss for SAF was less than $2 \%$ based on the results of 55 patients in a systematic review (6). The present case had neither fistula nor flap necrosis as some safety studies reported (4-8). Moreover, the SAF for this case was rational reconstruction due to non-use of a postoperative ventilator as well as the reduction of surgical staff during the COVID-19 pandemic.

Wide tumor resection with free flap reconstruction for patients with both HNC and synchronous EC has presented a challenge in the postoperative period, as the patients' quality of life was impacted by an inability to swallow and speak ( 9 , 10). However, our case achieved both pathologically negative tumor margins, decannulation, and had a thoracosopic esophagectomy with gastric tube reconstruction performed during the COVID-19 pandemic. Pedicle flaps including SAF in the management of head and neck cancer during the COVID-19 pandemic were recently reported as both a valid alternative to free flap (12) and the workhorse of reconstruction (13).

In conclusion, we documented a patient who had SAF reconstruction following the resection of his oral floor preceding esophagectomy. Following the surgery, the surgical margins were tumor negative and the patient was decannulated. Therefore, further research should be performed to document the results using SAF among patients with HNC.

\section{Conflicts of Interest}

The Authors declare no conflicts of interest.

\section{Authors' Contributions}

HS was the main operator of the initial surgery and assisted in the second surgery. SI and YK assisted in the initial surgery. EH and TA were the main operators of the second surgery, MS, SB, DN and $\mathrm{NH}$ contributed to the review of the manuscript.

\section{Acknowledgements}

This work was supported by JSPS KAKENHI Grant Number $21 \mathrm{~K} 09575$.

\section{References}

1 Zhu N, Zhang D, Wang W, Li X, Yang B, Song J, Zhao X, Huang B, Shi W, Lu R, Niu P, Zhan F, Ma X, Wang D, Xu W, Wu G, Gao GF, Tan W and China Novel Coronavirus Investigating and Research Team: A novel Coronavirus from patients with pneumonia in China, 2019. N Engl J Med 382(8): 727-733, 2020. PMID: 31978945. DOI: 10.1056/NEJMoa2001017

2 Mehanna H, Hardman JC, Shenson JA, Abou-Foul AK, Topf MC, AlFalasi M, Chan JYK, Chaturvedi P, Chow VLY, Dietz A, Fagan JJ, Godballe C, Golusiński W, Homma A, Hosal S, Iyer NG, Kerawala C, Koh YW, Konney A, Kowalski LP, Kraus D, Kuriakose MA, Kyrodimos E, Lai SY, Leemans CR, Lennon P, Licitra L, Lou PJ, Lyons B, Mirghani H, Nichols AC, Paleri V, Panizza BJ, Parente Arias P, Patel MR, Piazza C, Rischin D, Sanabria A, Takes RP, Thomson DJ, Uppaluri R, Wang Y, Yom SS, Zhu YM, Porceddu SV, de Almeida JR, Simon C and Holsinger FC: Recommendations for head and neck surgical oncology practice in a setting of acute severe resource constraint during the COVID-19 pandemic: an international consensus. Lancet Oncol 21(7): e350-e359, 2020. PMID: 32534633. DOI: 10.1016/S1470-2045(20)30334-X

3 Gascon L, Fournier I, Chiesa-Estomba C, Russo G, Fakhry N, Lechien JR, Burnell L, Vergez S, Metwaly O, Capasso P and Ayad T: Systematic review of international guidelines for head and neck oncology management in COVID-19 patients. Eur Arch Otorhinolaryngol : , 2021. PMID: 33891167. DOI: 10.1007/s00405-021-06823-4

4 Pallua $\mathrm{N}$ and Magnus Noah E: The tunneled supraclavicular island flap: an optimized technique for head and neck reconstruction. Plast Reconstr Surg 105(3): 842-51; discussion 852-4, 2000. PMID: 10724241. DOI: 10.1097/00006534-200003000-00003

5 de Carvalho FM, Correia B, Silva Á and Costa J: Versatility of the supraclavicular flap in head and neck reconstruction. Eplasty 20: e7, 2020. PMID: 32636986.

6 Sukato DC, Timashpolsky A, Ferzli G, Rosenfeld RM and Gordin EA: Systematic review of supraclavicular artery island flap vs free flap in head and neck reconstruction. Otolaryngol Head Neck Surg 160(2): 215-222, 2019. PMID: 30296901. DOI: 10.1177/0194599818803603

7 Thompson A, Khan Z, Patterson A, Java K and Varley I: Potential benefits from the use of the supraclavicular artery island flap for immediate soft-tissue reconstruction during the COVID-19 pandemic. J Maxillofac Oral Surg: 1-6, 2020. PMID: 32874025. DOI: $10.1007 / \mathrm{s} 12663-020-01440-\mathrm{w}$

8 Kent SL, Kim Y, Perez H, Frank E, Gentry V, LaTour D and Inman J: Consideration in microvascular reconstruction during 
times of social crises: perspectives on resource utilization. Facial Plast Surg 36(6): 768-772, 2020. PMID: 33368134. DOI: $10.1055 / \mathrm{s}-0040-1721811$

9 Okamoto T, Katada C, Komori S, Yamashita K, Miyamoto S, Kano K, Seino Y, Hosono H, Matsuba H, Moriya H, Sugawara M, Azuma M, Ishiyama H, Tanabe S, Hayakawa K, Koizumi W, Okamoto $\mathrm{M}$ and Yamashita T: A retrospective study of treatment for curative synchronous double primary cancers of the head and neck and the esophagus. Auris Nasus Larynx 45(5): 1053-1060, 2018. PMID: 29752155. DOI: 10.1016/j.anl.2017.12.005

10 Lin YH, Ou CY, Lee WT, Lee Y-, Chang T- and Yen YT: Treatment outcomes for one-stage concurrent surgical resection and reconstruction of synchronous esophageal and head and neck squamous cell carcinoma. Eur Arch Otorhinolaryngol 276(10): 2929-2940, 2019. PMID: 31332550. DOI: 10.1007/s00405-01905564-9

11 Rodrigo JP, Grilli G, Shah JP, Medina JE, Robbins KT, Takes RP, Hamoir M, Kowalski LP, Suárez C, López F, Quer M, Boedeker CC, de Bree R, Coskun H, Rinaldo A, Silver CE and Ferlito A: Selective neck dissection in surgically treated head and neck squamous cell carcinoma patients with a clinically positive neck: Systematic review. Eur J Surg Oncol 44(4): 395403, 2018. PMID: 29395434. DOI: 10.1016/j.ejso.2018.01.003
12 Pradhan P, Preetam C, Parida PK and Samal DK: Changing trend in the management of head neck cancers during the COVID-19 pandemic. Eur Arch Otorhinolaryngol: 1-8, 2021. PMID: 34120204. DOI: 10.1007/s00405-021-06898-z

13 Rashid HU, Rashid M, Khan N, Ansari SS and Bibi N: Taking a step down on the reconstruction ladder for head and neck reconstruction during the COVID-19 pandemic. BMC Surg 21(1): 120, 2021. PMID: 33685447. DOI: 10.1186/s12893-02101134-1
Received July 4, 2021

Revised July 26, 2021

Accepted July 27, 2021 